\title{
Irradiation of a nanocomposite of pseudoboehmite-nylon 6,12
}

\author{
A. H. MUNHOZ ${ }^{1, a}$, R. MENEGHETTI PERES ${ }^{1, b}$, L. H. SILVEIRA ${ }^{1, c}$ L. G. \\ ANDRADE E SILVA $^{2, \mathrm{~d}}$,L. F. DE MIRANDA ${ }^{1, \mathrm{e}}$ \\ ${ }^{1}$ Universidade Presbiteriana Mackenzie - U.P.MACKENZIE - Rua da \\ Consolação, 930 - Cep 01302-907 - Consolação - São Paulo - SP - Brazil \\ ${ }^{2}$ Instituto de Pesquisas Energéticas e Nucleares - IPEN - Brazil \\ a ahmunhoz@yahoo.com, ${ }^{\mathrm{b}}$ renato_mperes@yahoo.com.br, ${ }^{\mathrm{c}}$ \\ engmateriais@mackenzie.br, 'd Igasilva@ipen.br, ${ }^{\mathrm{e}}$ Ifmiranda@sti.com
}

\author{
Key-words: irradiation, pseudoboehmite, octadecylamine, nylon 6,12, \\ nanocomposite.
}

Nanocomposites are nanometrical material particles embedded in a specific matrix. The degree of organization of the nanostructures and their properties depend on the nature of the organic and inorganic components of the structure that can generate synergic interactions. Polymeric nanocomposites are related to a class of hybrid materials where inorganic substances of nanometric dimensions are dispersed in a polymeric matrix. In the present work, nanocomposites of nylon 6,12 with different concentrations of pseudoboehmite obtained by sol-gel process were prepared with and without the presence of octadecylamine. After preparation, the samples were irradiated with a $200 \mathrm{kGy}$ radiation dose in an electron accelerator. The pseudoboehmite nano particles were characterized by X-ray diffraction, scanning electron microscopy, differential thermal analysis and thermo gravimetric analysis. The nanocomposites were characterized by thermal and mechanical tests. The addition of pseudoboehmite promoted a reduction of the melting flow during the production of the composites evidencing the interaction of pseudoboehmite with the polymeric matrix, probably modifying its crystalline structure.

\section{Introduction}

All the hybrid organic-inorganic composites generally exhibit mechanical properties superior to those of their pure components [1]. The production and development of new nanocomposite materials has been increasing for almost all areas studied by material science, due to the possibility to modify properties like mechanical behavior, chemical, electrical and thermal stability. With the purpose to optimize the performance properties of the organic-inorganic composites, it is usually desirable to disperse the inorganic components in the organic matrix on a nanometer length scale. One successful process to achieving nanoparticles is the sol-gel process $[2,3]$.

In this work was prepared a nanocomposite of nylon 6,12 and a fine ceramic material, namely pseudoboehmite modified with octadecylamine. Pseudoboehmite is based on a monohydroxide aluminum oxide produced from the sol-gel synthetic route using ammonium hydroxide and aluminum nitrate as precursors. The octadecylamine is used like an organomodifier agent in organopseudoboehmite production.

These composites were characterized by the following techniques according to ASTM Standards: tensile strength, flexural strength, Izod impact, Vicat softening point, Deflection Temperature (HDT) and Shore D Hardness. 


\section{Experimental}

The pseudoboehmite was produced with $\left(\mathrm{Al}\left(\mathrm{NO}_{3}\right)_{3} .9 \mathrm{H}_{2} \mathrm{O}\right)(980 \mathrm{~g}$ aluminum nitrate/1 L water), $\mathrm{NH}_{4} \mathrm{OH}$ water solution $(28 \mathrm{wt} \%)$ and polyvinyl alcohol $\left(\left[\mathrm{C}_{2} \mathrm{H}_{4} \mathrm{O}\right] \mathrm{n} ; \mathrm{PVAl}\right)$ solution $(8 \mathrm{wt} \%$ in water $)$ to increase the viscosity. The sol-gel procedure used to produce the pseudoboehmite is described in a previous paper $[4,5]$.

Characterization methods for the pseudoboehmite

$X$-rays powder diffraction. For the samples dried at $70^{\circ} \mathrm{C} / 24$ hour's diffraction data were recorded with a Rigaku MultiFlex difractometer with a fixed monocromator. The experimental conditions were: $40 \mathrm{kV}, 20 \mathrm{~mA}, 20^{\circ}<2 \theta<100^{\circ}, \Delta 2 \theta=0.02^{\circ}, \lambda_{\mathrm{CuK} \alpha}$ at room temperature. The collected data were compared with the ICDD data.

Scanning electron microscopy: scanning electron microscopy (SEM) images were taken with a Phillips XL30 equipment using secondary electron detector. The powder was placed upon SEM stubs covered with double-face tape and with gold in an Edwards Sputter Coater model S150B. The images were registered under magnifications of $200 \mathrm{X}$ and $6000 \mathrm{X}$.

Thermal analyses: the thermogravimetric analysis (TG) and differential scanning calorimetry (DSC) were performed in a Netzsch-STA409C equipment; heating from room temperature to $1300^{\circ} \mathrm{C}$, with $10^{\circ} \mathrm{C} \mathrm{min}^{-1}$ heating rate, $50 \mathrm{~cm}^{3} / \mathrm{min}$ nitrogen.

The composites

The composites were prepared according to the composition of Table 1. The pseudoboehmite was impregnated with the octadecylamine according to the procedure of the reference 6 .

Table 1: Sample compositions (Wt\%)

\begin{tabular}{l|c|c|c}
\hline Sample & Nylon 6,12 & Pseudoboehmite & Octadecylamine \\
\hline N100 & $100 \%$ & - & - \\
\hline N99P01-40 & $99 \%$ & $0,6 \%$ & $0,4 \%$ \\
\hline N99P01-20 & $99 \%$ & $0,8 \%$ & $0,2 \%$ \\
\hline N97P03-40 & $97 \%$ & $1,8 \%$ & $1,2 \%$ \\
\hline N97P03-20 & $97 \%$ & $2,4 \%$ & $0,6 \%$ \\
\hline
\end{tabular}

Measurements of the composite properties

The composites were obtained with the weight composition described in Table 1. The sample N100 had the same preparation procedure of the other samples before analysis.

The mechanical measurements were performed in the samples at room temperature. The notched Izod Impact strength, tensile strength and flexural properties (flexural strength and flexural modulus) were determined according to ASTM D-790. The Shore D Hardness was obtained using Mitutoyo Hardmatic equipment. The Vicat softening point (ASTM D1525) and Deflection Temperature data (HDT) obtained according to ASTM D648 was determined using a Tinius Olsen HD94/398 equipment.

\section{Results and discussion}

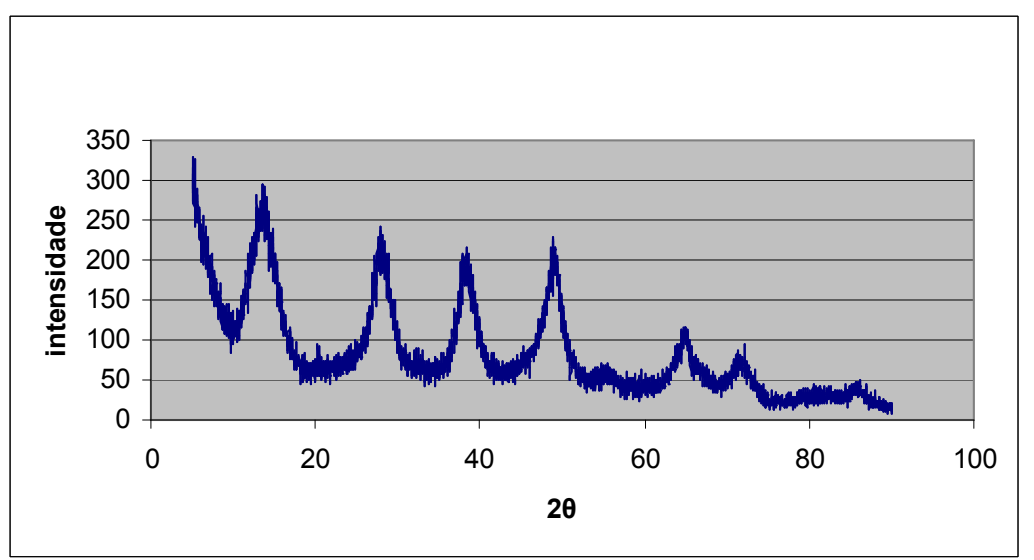

Figure 1. X-ray diffraction of pseudoboehmite sample. 
The X-ray diffraction data, in Figure 1, shows the typical pseudoboehmite diffraction pattern with low intensity peaks observed, for example, at $2 \theta=13^{\circ}(020)$ and $28^{\circ}(021)$.

The typical curve of the DSC for pseudoboehmite shows an endothermic peak near the temperature of $100^{\circ} \mathrm{C}$, due to water vaporization. The transformation of pseudoboehmite to $\gamma$ alumina and the decomposition of PVAl in the same range temperature of the DSC analysis show a complex peak in the range of $200-400^{\circ} \mathrm{C}$. The TG analysis shows the loss of weight correspondent to these phenomena (Figure 2). In the DSC analysis at around $1200^{\circ} \mathrm{C}$ is observed a peak attributed to the transformation of the last meta-stable phase of alumina to $\alpha$-alumina.

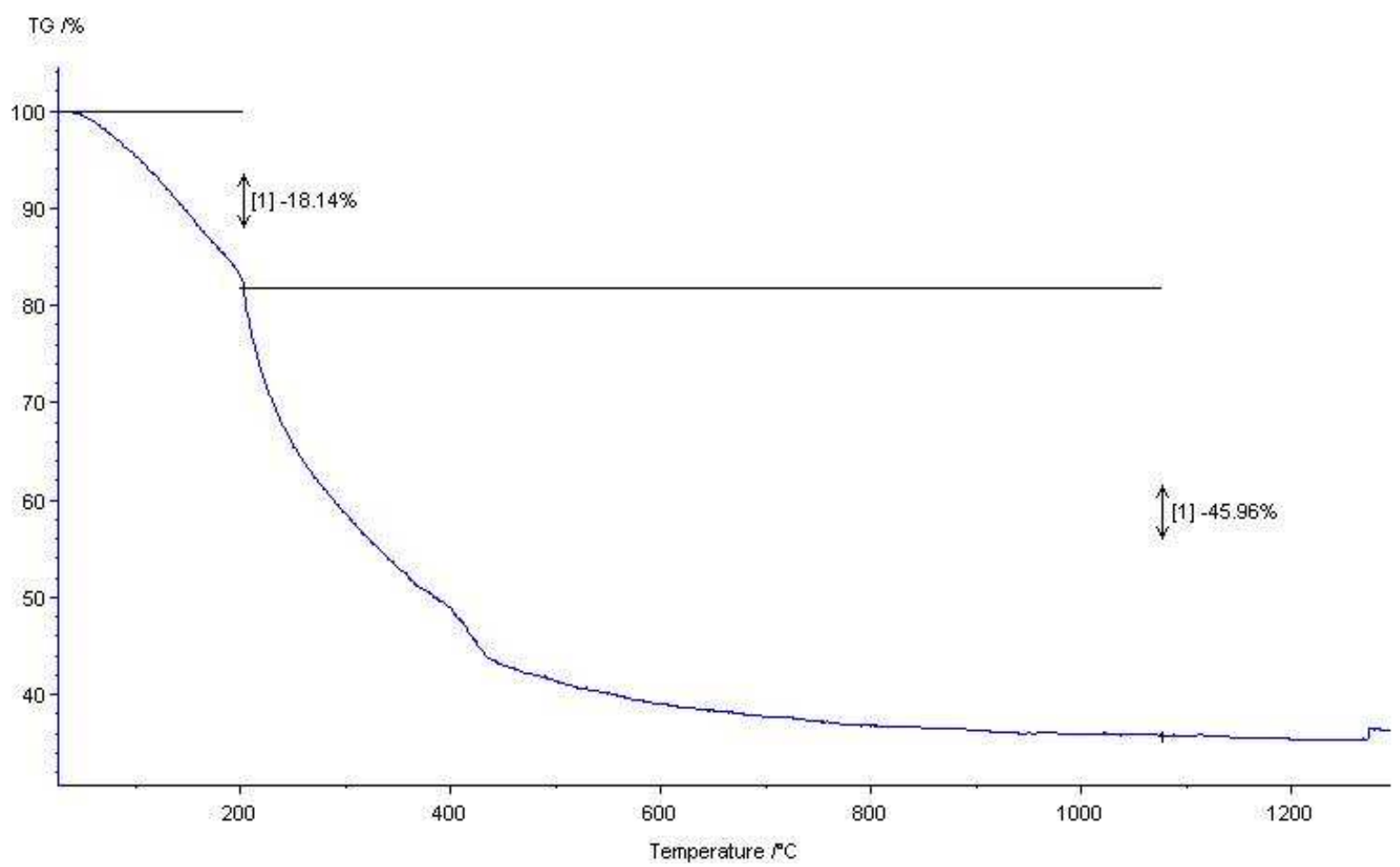

Figure 2. TG analysis of pseudoboehmite.

The material surface has a high porosity level, as can be seen trough the SEM analysis in Fig. 3. The high specific surface area $\left(300 \mathrm{~m}^{2} / \mathrm{g}\right)$ was observed in the samples synthesized by this route [5].

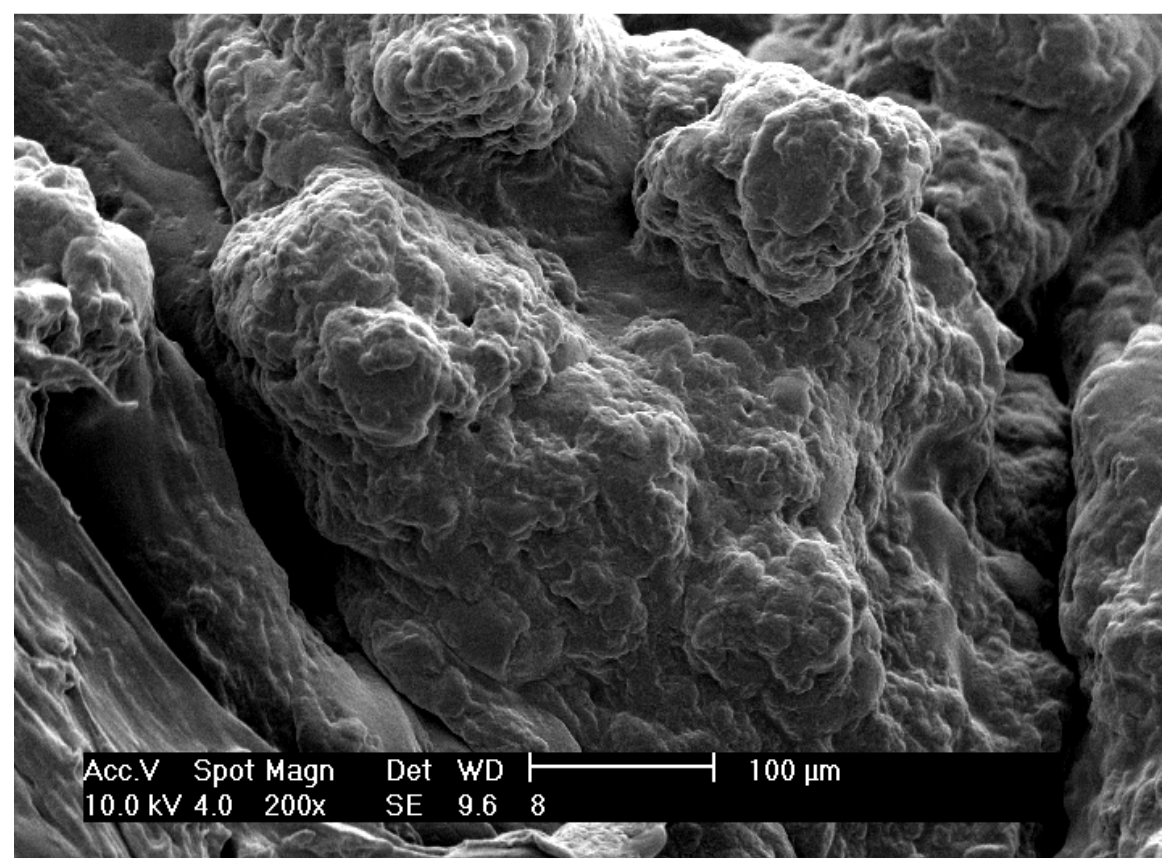

Figure $3 \mathrm{SEM}$ of pseudoboehmite after drying at $70^{\circ} \mathrm{C} / 24 \mathrm{~h}$. 
Measurements of the composite properties

Using naked eyes it could be observed that the composite N99P01-20 is the more homogeneous composite.

The results of the impact energy absorbed by the specimen during failure show that the addition of pseudoboehmite increased the izod test results (Figure 4).

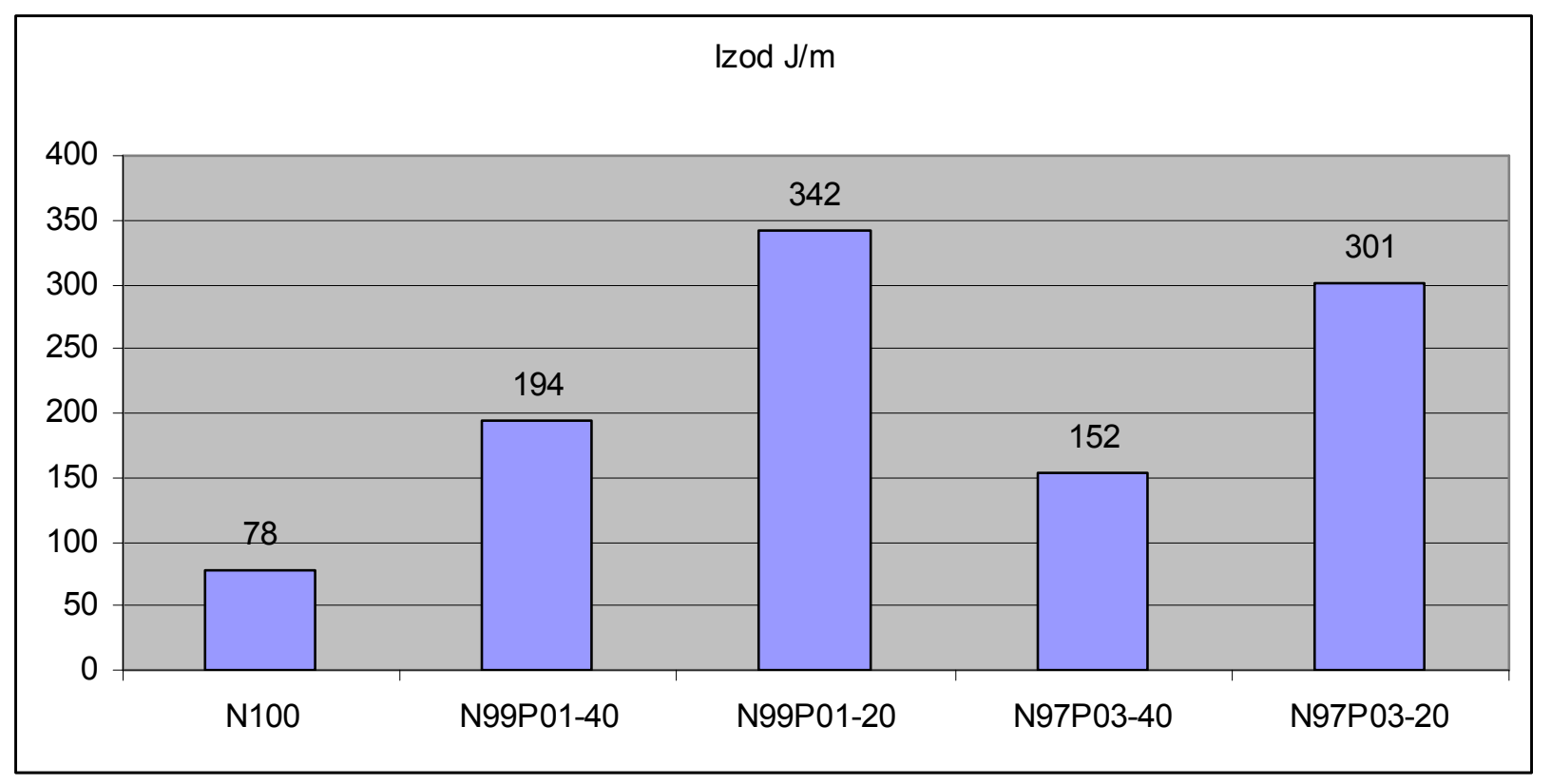

Figure 4. Impact Izod of the composities

The compositions containing the small amount of octadecylamine show a bigger value of energy absorbed in the specimen failure. An impact test is often used to evaluate the brittleness of a material when the material is subjected to a sudden, intense blow, in which the strain rate is extremely rapid. In the impact test the material may behave in much more brittle a manner than is observed in the tensile test.

The tensile strength test shows that the addition of pseudoboehmite at nylon 6,12 do not increase the stress at yield, neither the stress at break. It was observed that the samples containing the small amount of octadecylamine have the biggest stress at yield. The samples containing higher amounts of pseudoboehmite have the biggest tensile modulus (Table 2).

Table 2. Tensile Strength data

\begin{tabular}{c|c|c}
\hline Sample & Tensile strength at break (MPa) & Tensile Modulus (MPa) \\
\hline N100 & $48.9 \pm 0.7$ & $767.2 \pm 76$ \\
\hline N99P01-40 & $48.7 \pm 2.4$ & $724.7 \pm 63$ \\
\hline N99P01-20 & $47.4 \pm 1$ & $739.2 \pm 65.9$ \\
\hline N97P03-40 & $48.8 \pm 0.7$ & $960.6 \pm 35.3$ \\
\hline N97P03-20 & $49.1 \pm 0.3$ & $956.9 \pm 51.2$ \\
\hline
\end{tabular}

The bend test data (Figure 5) shows that the addition of the pseudoboehmite do not resulted in a big increase of the flexural strength of the composites. The sample N99P03-40 has the biggest result for this test. The deformation until the maximum load was very similar to all composites and the value was near $19.7 \mathrm{~mm}$.

The shore D hardness data (Figure 6) shows that the samples containing the larger amount of pseudoboehmite show an increase in the shore D hardness. 


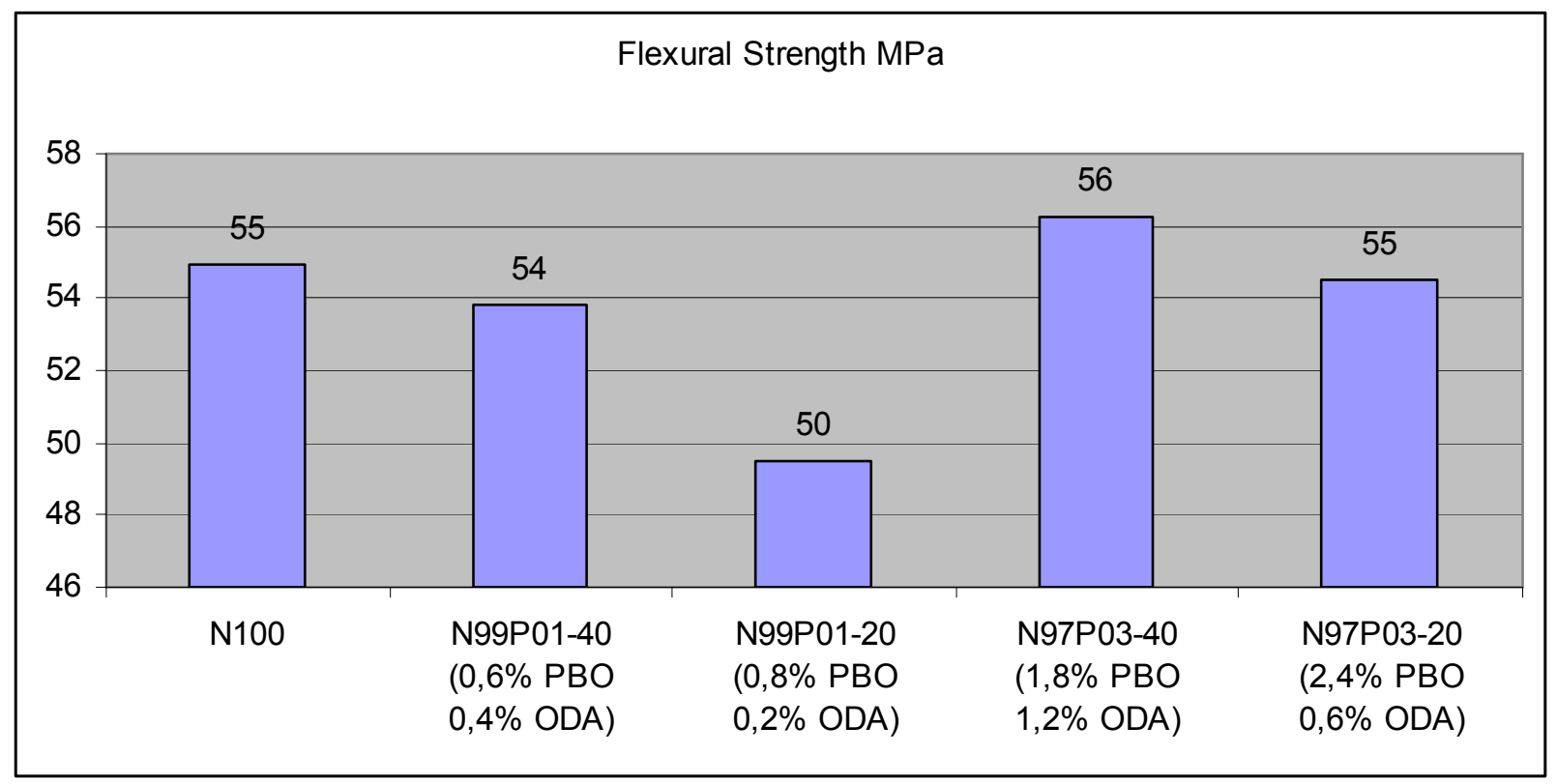

Figure 5. Results of the bend test data.

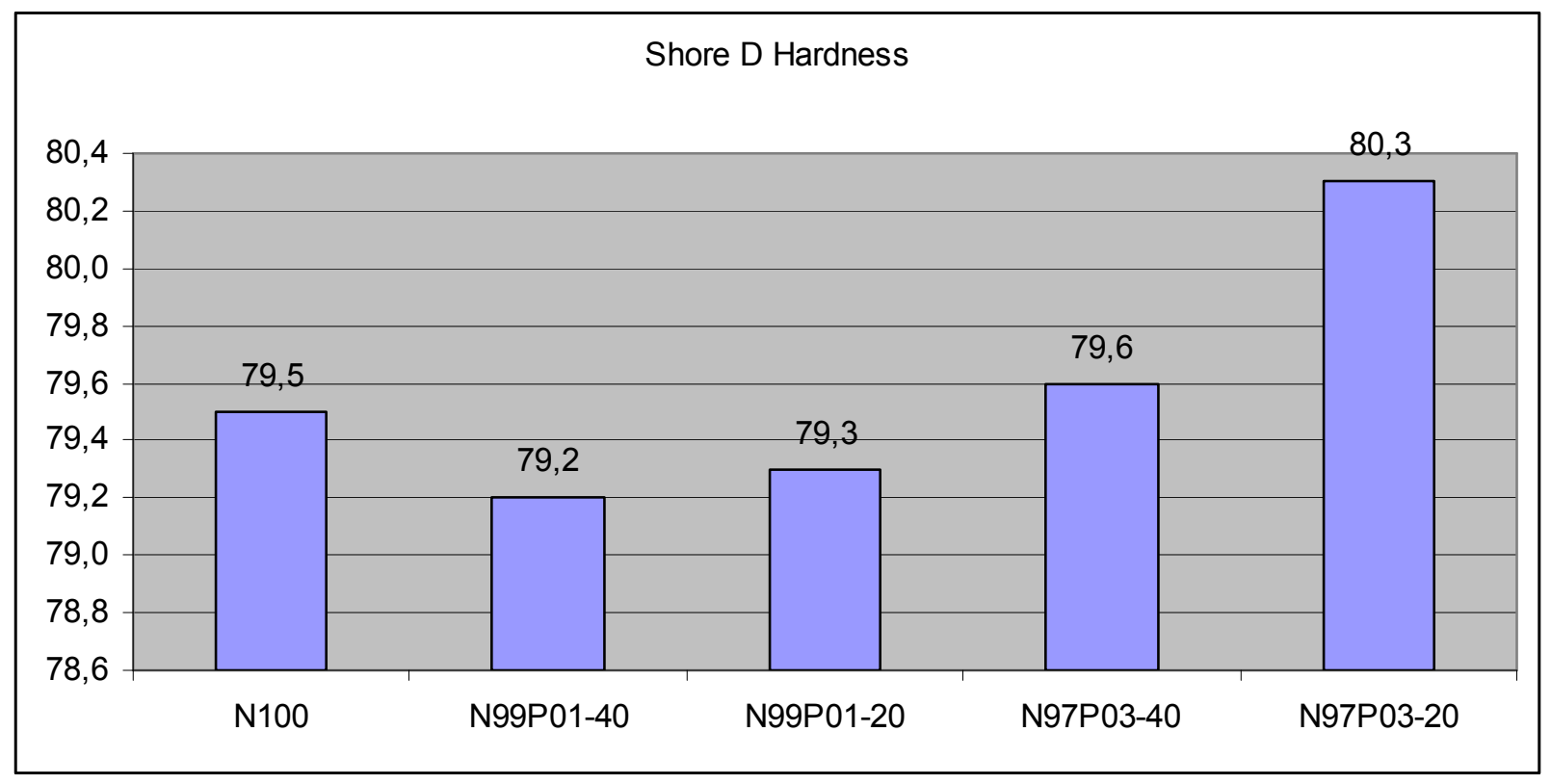

Figure 6. Shore D Hardness data.

A comparative examination of the Vicat softening data is presented in Table 3. Small differences were observed among the five composites.

Table 3. Vicat softening data.

\begin{tabular}{l|ccccc}
\hline Sample & N100 & N99P01-40 & N99P01-20 & N99P03-40 & N99P03-20 \\
\hline Medium & 198,1 & 197,8 & 197,6 & 197,8 & 198,1 \\
\hline $\begin{array}{l}\text { Standard } \\
\text { Deviation }\end{array}$ & 0,6 & 0,0 & 0,3 & 0,1 & 0,3 \\
\hline
\end{tabular}

The Deflection Temperature data (HDT) shows that the addition of pseudoboehmite and octadecylamine promoted an increase in the HDT results (Figure 7). 


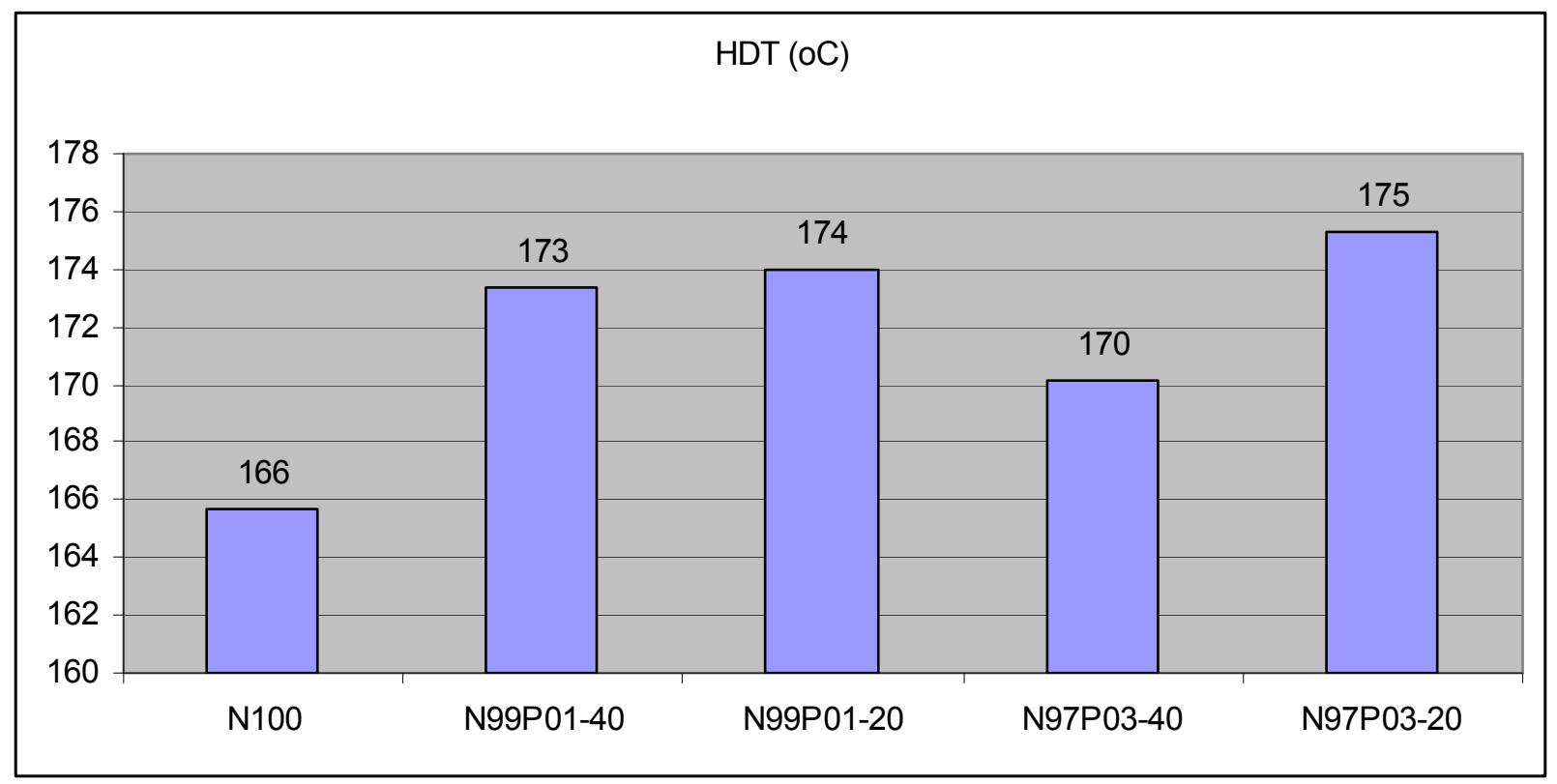

Figure 7. HDT data of the composites.

\section{Conclusions}

The x-ray diffraction data and the DSC analysis show the typical results for pseudoboehmite, as related in the literature. The scanning electron micrograph shows that the product of the sol-gel synthesis is a very porous material.

The addition of pseudoboehmite/octadecylamine promoted an increase in the energy absorbed by the specimen during the failure observed in the Izod impact strength test. For the tensile strength and bend test it was not observed the same level of increase in the result as in the izod impact test. By the Vicat results it was observed that the addition of the pseudoboehmite/octadecylamine did not promote a big difference in the results. The HDT data show that the addition of pseudoboehmite and octadecylamine promoted the increase in the HDT results.

\section{References:}

[1] T.J. Pinnavaia; G.W. Beall, Polymer-Clay Nanocomposites, John Wiley \& Sons, Toronto, 2000.

[2] Philipp, G.; Schmidt, H. J. Non-cryst.solids, 1984, 63, 283.

[3] Philipp, G.; Schmidt, H. J. Non-cryst.solids, 1996, 82, 31.

[4] A.H. Munhoz Jr.; L.F.Miranda; G.N.Uehara; Study of pseudoboehmite by sol-gel sinthesis, AST-Advances in Science and Technology, v.45, p.260-265, 2006.

[5] J. A. G. Carrió, S. B. Faldini, L. F. de Miranda, P. K. Kiyohara, L. G. A. Silva, A. H. Munhoz Jr.1, Zeitschrift fur Kristallogr. Suppl. 26 (2007) 537-542.

[6] ZAPATA, P.; QUIJADA, R.; RETUERT, J.; MONCADA, E.; Preparation of Nanocomposites by In Situ Polimerization. Jornal of Chilean Chemical Society. v. 53, n. 1, p. 1369- 1371, 2008

\section{Acknowledgement:}

This research has been supported by the MackPesquisa and the Universidade Presbiteriana Mackenzie. We thank both for the support. 